\title{
How to Support Children with Mathematical Learning Disabilities Learning to Play an Instrument?
}

\author{
Annemie Desoete \\ Department of Experimental Clinical and Health Psychology Developmental Disorders, Ghent University, \\ H. Dunantlaan, 2 B-9000 Ghent, Belgium \\ Correspondence should be addressed to Annemie Desoete, annemie.desoete@ugent.be
}

Received 10 March 2012; Accepted 5 April 2012

Academic Editor: Terry Stratton

Copyright ( 2012 Annemie Desoete. This is an open access article distributed under the Creative Commons Attribution License, which permits unrestricted use, distribution, and reproduction in any medium, provided the original work is properly cited.

In this study, children with a mathematical learning disability $(n=14)$ and age-matched peers without learning disabilities $(n=$ 14) as well as their parents and teachers were interviewed on how they experienced playing an instrument (guitar, drum, flute, violin, trombone, horn, and piano) and on what helped them using a qualitative interactive interview with a flexible agenda to discover the interviewee's own framework of meanings. Thematic analyses mentioned intrinsic motivation, extrinsic motivation, and self-efficacy as important. Some children with MLD were found to have a real musical talent and a very good musical ear and memory for sounds. However, all children with MLD seemed more dependent on the aid of parents, sibling, peers, and teachers. They had to study harder and needed more time to study, more practice, and a more structured approach.

\section{Introduction}

It is hard not to overemphasize the importance of mathematical literacy in our society. In everyday life situations, we need to be on time, pay bills, follow directions or use maps, look at bus or train timetables or comprehend instruction leaflets and expiry dates. A lack of mathematical literacy was found to affect people's ability to gain full-time employment and often restricted employment options to manual and often low-paying jobs [1].

Even in music mathematical skills are needed to perceive rhythmic patterns. Moreover, music depends on symbols (notes) and fractions, as well as on rapid note number, note order, pitch, timbre, and melody detection and discrimination as well as on temporal processing and timing skills.

Differences in mathematics between and within individuals are normal. Teachers are expected to cope with learning differences and to adjust their teaching style to the needs of all students. However, in some cases these differences appear to be so severe or resistant that they can be considered as characteristics of "problems" or even "disabilities."

Despite the growing interest observed over the last few years, research on mathematical learning disabilities (MLDs) is actually much less advanced than on dyslexia [2]. The term
MLD refers to a significant degree of impairment in the arithmetical skills (with substantially below performances). In addition, children do not profit from (good) help. This is also referred to as a lack of responsiveness to intervention (RTI). Finally, the problems in MLD cannot be totally explained by impairments in general intelligence or external factors. Most practitioners and researchers currently report a prevalence of MLD between 3-14\% of the school-age population depending on the country of study [1,3-5]. Geary et al. [6] revealed that children with a severe MLD had a severe math cognition deficit and underlying deficit in working memory and speed of processing. The groups with mild MLD had more subtle deficits in few math domains. This study is devoted to impact of MLD on music skills and especially on how to support children with MLD to learn to play and enjoy an instrument (guitar, drum, flute, violin, trombone, horn, and piano).

Although there are studies indicating a relationship between dyslexia and music [7-12], there is only a limited number of studies on the relationship between MLD and music $[13,14]$.

In addition, in none of the studies on music and learning disabilities, there was a multimethod design with a triangulation of tests and phenomenologically based interviews, as 
described by Seidman [15] gathered from children, parents, and teachers to reflect on the meaning of and problems with playing an instrument while having MLD.

\section{Method}

2.1. Participants. In this study, the performances of 5 boys and 9 girls with MLD (mean age 13.1 years, SD $=3$ years) and 14 age-matched children without learning disabilities playing an instrument (guitar, drum, flute, violin, trombone, horn, and piano) were compared.

The children with MLD had all been diagnosed as at least average intelligent (TIQ > 80) with MLD former to this study by trained diagnosticians. Only children with such a clinical diagnosis, problems with arithmetic across at least two successive grades and remediation not leading to improvements were accepted in the cohort of children with MLD. Two of the children had MLD and in addition also dyslexia. One child had MLD and an attention deficit. Their diagnosis was (re)confirmed by us with a test on arithmetic fact retrieval or procedural calculation.

For each child with MLD, a control child was searched and matched on age, gender, and music instrument the child learned to play. For the recruitment, music schools within Flanders (a Dutch speaking part of Belgium) contacted children with matching profiles. This action was repeated until all participants for the control group were found. A mathematics, reading, and spelling tests were administered to all controls in order to exclude possible learning deficiencies.

Both groups of children did not differ in age ( $U=87.5$, $P=\mathrm{NS})$.

2.2. Instruments. In order to obtain a complete overview of the mathematical abilities of children, two math tests were used: the Revised Kortrijk Arithmetic Test (Kortrijkse Rekentest Revisie KRT-R [16]) and the Arithmetic Number Facts Test (Tempo Test Rekenen TTR [17]).

The Arithmetic Number Facts Test [17] is a numerical facility test consisting of five subtests with arithmetic number fact problems: addition, subtraction, multiplication, division, and mixed exercises. Children have to solve as many items as possible in five minutes; they can work one minute on every colon. The TTR is a standardized test that is frequently used in Flemish education as a measure of number fact retrieval (e.g., [18]).

The Kortrijk Arithmetic Test Revision [16] is a standardized test on which requires that children solve mental arithmetic and number knowledge tasks. The KRT-R is frequently used in Flemish education as a measure of procedural mathematical skills (e.g., $[18,19])$. In TTR and KRT-R, raw scores were the numbers of correct items and were converted in $z$-scores.

Furthermore, all children were tested with standardized Dutch reading and spelling measures. Word reading speed or fluency was assessed by the one-minute reading test (EMT [20]) and pseudoword reading by the Klepel [21]. Both reading tests consist of lists of 116 unrelated words. Children are instructed to read as many words as possible in one
(EMT) or two minutes (Klepel) without making errors. On both tests, the raw scores were the numbers of words read correctly.

Spelling was assessed with PI-dictation [22], a Dutch standardized test in which children have to write down the repeated word from each sentence. The test consists of nine blocks of 15 words. Each block has a higher difficulty level and testing is stopped once a child made seven or more errors in a block. Raw score was the number of words spelled correctly.

2.3. Procedure. This study was part of a larger study approved by the Ethical Committee of Ghent University.

Following the principles of grounded theory, there was an interplay between data collection and data analysis [23, 24]. The teachers of children playing an instrument and children with and without MLD and their parents were informed about this study and invited to participate. After their consent, children and parents were visited at home. Teachers were visited at their school. Children were tested on intelligence, arithmetic, reading, and spelling. They were also filmed while playing their instrument and during an indepth interview they were asked to talk about their music and about the support to learn to play an instrument in general. Each interview lasted for about 80 minutes. Following informed consent, all interviews were recorded and transcribed verbatim. Data analysis were conducted with NVIVO8, a computer-based qualitative data management program, to facilitate the analysis. During this continuous process of open and axial coding and constant comparison of the codes, recurrent and emerging themes were found. Based upon the findings of the first 5 children with MLD, their parents and teachers, the interview topic list was refined and completed. The analysis of the next children was similar, and a first scheme of "good music support in children with MLD" emerged. This schema was discussed with the children, parents and teachers as member check. Because of this continuous process of data collection and data analysis, we were satisfied that we had acquired sufficient data to describe the protective factors and elements of a good support in our schemes. Moreover, we decided to use two mind maps to present the results of this study. Once our recipe for music support was completed (see Figure 1 and Table 1), we presented this to two children and their parents and to one teacher to assure us of the accuracy and the completeness of this recipe. Triangulation was achieved by using multiple respondents (children, parents, and teachers) to analyze data. Transferability was enhanced by including children with a variety of characteristics and age and instruments.

\section{Results}

3.1. Arithmetic, Reading, and Spelling. There were no significant differences between children with MLD and the age matched peers without learning problems on intelligence $(t 26=-1.286, P=\mathrm{NS})$ the decoding skills of existing words measured with the EMT $(t 26=-.986, P=\mathrm{NS})$ or nonsense words on the KLEPEL $(t 26=-1.673, P=\mathrm{NS})$. 


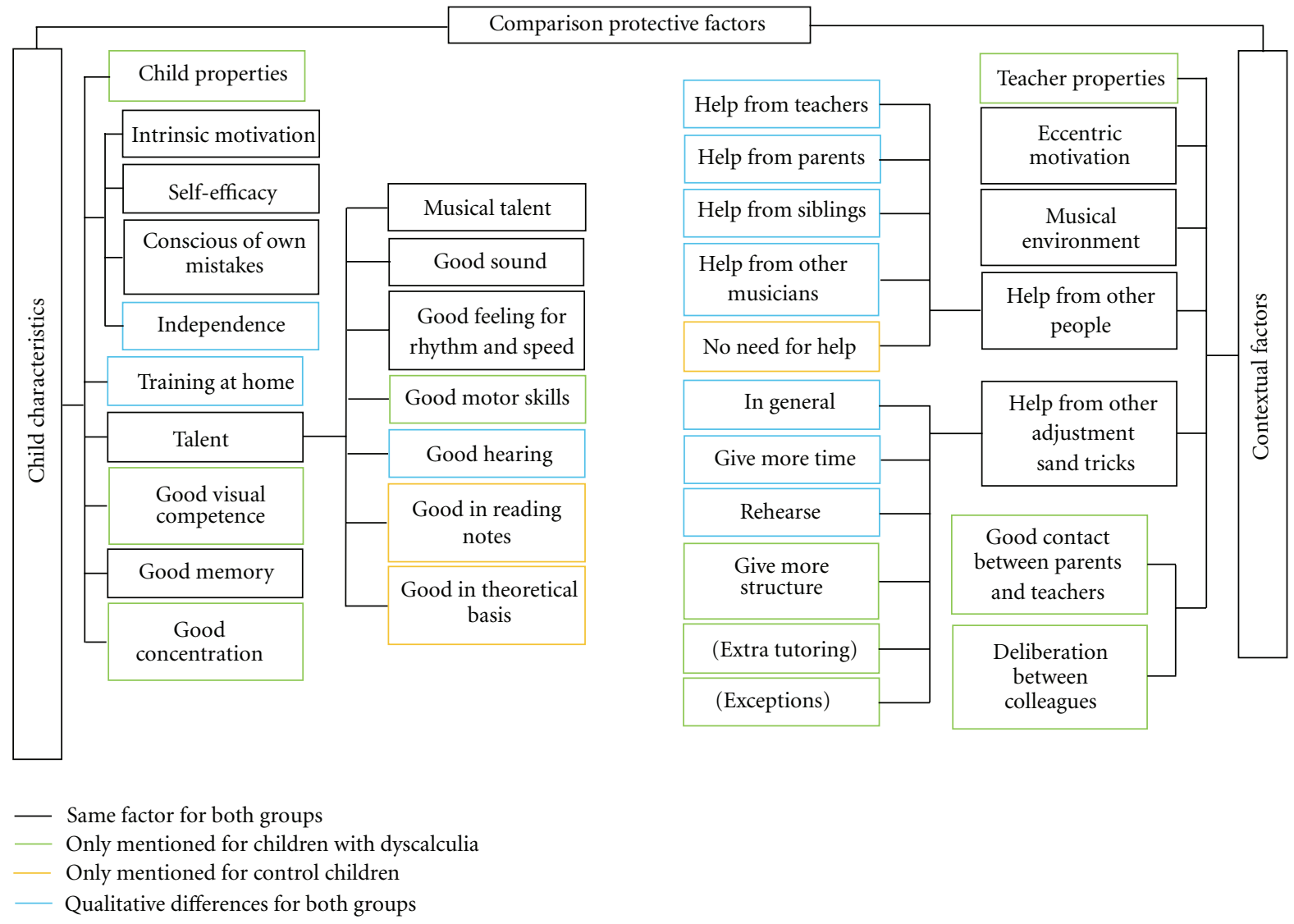

Figure 1: What makes a child successful in music?

However, children with MLD had lower spelling skills on PIdictation $(t 14.749=-2.837, P \leq 0.5)$ and more problems with arithmetic fact retrieval on the TTR $(t 26=-3.008$, $P \leq 0.05)$, and procedural calculation on the KRT-R ( $t 26=$ $-4.213, P \leq 0.005)$ compared to children without learning disabilities.

3.2. Music Performances. Three independent persons, blind to the aims of the study, listened to all children playing an instrument. They were asked to rate children as having problems with music or not. All persons rated 13 out of the 14 children with MLD as having problems with music. They only rated 2 out of the 14 children without learning problems as having problems with music.

\subsection{Interview Results on the Protective Factors to Continue} Learning to Play an Instrument in Children with MLD. As child factors, parents and teachers described the children with MLD as happy $(n=6)$ and socially involved $(n=14)$.

"Always smiling. He is also very socially involved, certainly during the courses but also towards other students. He is very open." (teacher Dieter)

They were also often seen as "strong" children $(n=9)$ that persevere and hide their problems from the outside world. In addition intrinsic motivation $(n=10)$, liking to sing $(n=7)$ and self-efficacy or believing that one is good at playing an instrument $(n=8)$ were important protective child factors in children with MLD.

"My first exam was a real disaster, but for the second one I had studied very hard. I think they noticed this also and I played good and like the drum I played." (Guido, 13 years)

Moreover being conscious of the own mistakes $(n=8)$ and trying to play independently difficult passages $(n=$ 11) seemed important. However the most important factor according to children $(n=10)$, parents $(n=6)$, and teachers $(n=21)$ was "trying hard" and spending a lot of time on "exercises." Children with MLD had to work harder and more to obtain the same results as children without MLD.

"I practiced longer and more than the other children in my class. But I want to play it. Music is very important for me." (Femke, 13 years)

Another protective factor to be successful was the musical talent of the child. Some children $(n=4)$ were very skilled in the playing of the instrument. Some of them had a good feeling of rhythm $(n=3)$, although in most children with MLD this was not the case $(n=11)$. What also helped was a good musical ear and auditory memory $(n=6)$. However, other children compensated their visual competences. Finally 
TABLE 1: STICORDI for music teaching in children with and without MLD.

\begin{tabular}{|c|c|c|}
\hline During the notes class and instruments class & During the notes class & During instruments class \\
\hline Give complements and encourage & $\begin{array}{l}\text { Position the pupil at the front of the } \\
\text { classroom }\end{array}$ & Provide a good (nice) instrument \\
\hline $\begin{array}{l}\text { Nominate what goes well (in addition to } \\
\text { what is not going well) }\end{array}$ & $\begin{array}{l}\text { Check if pupils understand and know how } \\
\text { to use the tips and tricks }\end{array}$ & $\begin{array}{l}\text { Provide a nice textbook and nice music } \\
\text { pieces }\end{array}$ \\
\hline $\begin{array}{l}\text { Indicate on the score difficult passages or } \\
\text { rhythms (with colors) }\end{array}$ & $\begin{array}{l}\text { Use rhythm language to teach rhythms } \\
\text { (possibly as continuous support) }\end{array}$ & $\begin{array}{l}\text { Provide variation in the tasks and music } \\
\text { scores }\end{array}$ \\
\hline $\begin{array}{l}\text { Let play or sing along with a CD, where } \\
\text { there is accompaniment }\end{array}$ & $\begin{array}{l}\text { Enlarge music paper when kids have to } \\
\text { write the notes themselves }\end{array}$ & $\begin{array}{l}\text { Place the pupil in a group that fits their } \\
\text { level and friendships }\end{array}$ \\
\hline $\begin{array}{l}\text { Learn to feel the rhythms by gently tapping } \\
\text { the child on the shoulder or arm }\end{array}$ & $\begin{array}{l}\text { Provide more time for making of } \\
\text { homework }\end{array}$ & $\begin{array}{l}\text { Write down the finger settings } \\
\text { corresponding to the notes (possibly note } \\
\text { names) }\end{array}$ \\
\hline $\begin{array}{l}\text { Divide the music into pieces and learn them } \\
\text { step by step }\end{array}$ & Provide easy exercises & Allow to play less or shorter pieces \\
\hline $\begin{array}{l}\text { Give sufficient time to exercise the music } \\
\text { and to repeat }\end{array}$ & $\begin{array}{l}\text { Use step-by-step plans (possibly also } \\
\text { during tests) }\end{array}$ & Simplify the musical scores \\
\hline \multirow[t]{6}{*}{ Use an agenda } & Announce tests long beforehand & $\begin{array}{l}\text { Adjust the repertoire to the level and } \\
\text { motivation of the pupil (possibly opt to } \\
\text { follow playing together) }\end{array}$ \\
\hline & Provide more time to finalize tests & $\begin{array}{l}\text { Play the music that is to be played to the } \\
\text { pupil beforehand or play it once }\end{array}$ \\
\hline & $\begin{array}{l}\text { Divide tests into } 2 \text { parts and spread them } \\
\text { over days }\end{array}$ & Allow to exercise with a metronome \\
\hline & $\begin{array}{l}\text { Provide more preparation time for singing } \\
\text { lessons during the exams (i.e., allowing to } \\
\text { follow how other kids perform on an } \\
\text { exam) }\end{array}$ & $\begin{array}{l}\text { Allow pupil to follow/tap the rhythm with } \\
\text { his/her foot or have the teacher tap the } \\
\text { rhythm for the pupil }\end{array}$ \\
\hline & $\begin{array}{l}\text { Allow to prepare at home for the } \\
\text { examination }\end{array}$ & $\begin{array}{l}\text { Put text to the notes so that it becomes a } \\
\text { song }\end{array}$ \\
\hline & $\begin{array}{l}\text { Discharge of examinations, tasks and tests } \\
\text { during notes class }\end{array}$ & $\begin{array}{l}\text { Teach longer or spread over a longer time } \\
\text { (i.e., twice a week) }\end{array}$ \\
\hline
\end{tabular}

two parents and two teachers described a good concentration as protective factor to be successful in the playing of an instrument.

"She has good musical skills. She has feeling for the instrument." (teacher Dorien)

Teachers were very important contextual factor for the enjoying of music in children with MLD. Children $(n=$ 7) found it important to have a "nice" teacher, a teacher with a lot of "patience," and a teacher who made them feel comfortable. Also parents $(n=8)$ and teachers $(n=10)$ found patience very important. Having the same teacher for a longer period was for children very important.

"She's never angry and very patient. She explains every thing very well. You can ask and she will show it again." (Margo, 17 years)

Moreover also extrinsic motivation or getting a good instrument to play $(n=3)$, or social affordances such as complements seemed important. Children $(n=11)$ often reported that they liked to play an instrument because their friends also played music.
"Note lessons are boring. I never liked to go. However the last years when my friends also went to the lessons I enjoyed these moments." (Margo, 17 years)

In addition, 12 of the 14 (or $85 \%$ ) of the children with MLD (playing an instrument) had at least one of the parents playing and enjoying music. Also 13 of them (or 92\%) had a sibling that played an instrument. In addition, all children with MLD seemed more dependent on the aid of parents, sibling, peers, and teachers compared to age-matched peers without learning problems.

"We all play an instrument." (parents of Dieter)

Parents $(n=12)$ or siblings $(n=4)$ helped them with their homework. This was nearly never $(n=1)$ the case in children without learning problems. Also peers or other musicians $(n=10)$ and the teacher $(n=8)$ offered extra support. Extra tutoring $(n=3)$, more time $(n=10)$, more exercises $(n=3)$, a lot of opportunities for rehearsal $(n=1$ child, $n=9$ teachers $)$, and more structure $(n=1$ child, $n=9$ teachers) to children with MLD.

"Ah for the violin. Mother helps me by playing on the piano so that I faster." (Femke, 13 years) 
3.4. Interview Results on the Protective Factors to Continue Learning to Play an Instrument in Control Children. To look for the specificity of problems in children with MLD also age-matched peers were interviewed. As child characteristics control children told that they liked playing songs $(n=5)$. Twelve of them preferred the instrument classes over the note classes. In addition, 12 children were intrinsically motivated because they choose the instrument they played themselves. Out of the interviews, 13 out of 14 children demonstrated self-efficacy and their belief in their own musical skills. They also described to be aware of the mistakes they made $(n=$ 5 ) and told that they made their homework independently $(n=8)$. Sometimes parents or siblings checked it afterwards. The children told that they made a lot of exercises at home to "become" better $(n=10)$. These control children also described that they find music easy $(n=9)$, and that they have no problem with rhythm or tempo $(n=6)$. Some children $(n=5)$ told to have a "good musical ear" $(n=5)$. Almost all $(n=13)$ control children described to be good at reading notes and musical scores. Three children told to have a good memory for music and to be able to repeat and play a music score when they just heard it.

As contextal factors also control children $(n=7)$ liked to get a compliment (as extrinsic motivation). Three children told that they like music because their friends also play an instrument. In this group of children, 2 children have parents, and 8 children had siblings playing an instrument.

3.5. Interview Results on Good Support during Notes Class and Instrument Class for Children with MLD. When looking for "reasonable adjustments" or good support and instruction by music teachers it seemed important in notes class and in instrument class that teachers nominated what went well (in addition to what did not go well). Feedback was a powerful tool to enhance self-esteem and self-efficacy in all children learning to play an instrument.

"If I want to help them I spend three to four times as much time in coaching hem as I spend in other children. I learn what is correct and what not. This helps." (teacher Dieter)

However, some special adjustments during notes class and instruments class helped often a lot. Indicating on the score difficult passages or rhythms (with colors), letting play or sing along with a CD, gently tapping the child on the shoulder or arm to feel the rhythm, dividing the music into pieces and learn them step by step, giving sufficient time to exercise the music and to repeat ( $n=10$ children, $n=18$ teachers), and using an agenda were very helpful according to children with MLD, parents, and teachers.

"At school my mother learned me to write down everything. I learn and memorize it more easily that way. I make scheme, summaries and so on. That helps." (Toon, 12 years)

"We use colors, divide the music in pieces and give more structure. She has make a lot of extra exercises at home also. She plays as a younger girl, not at the level of an 18 year old girl, but rather as someone of 14 or 15 years old." (teacher Mieke)

Moreover, children told that during the notes class a position at the front of the classroom, checking if they understood and knew how to use the tips and tricks, using rhythm language to teach rhythms (possibly as continuous support), enlarging music paper when kids had to write the notes themselves, providing more time for making homework, providing easy exercises, using step-by-step plans (possibly also during tests), announcing tests long beforehand, providing more time to finalize tests, dividing tests into 2 parts and spread them over days, providing more preparation time for singing lessons during the exams (by allowing to follow how other kids perform on an exam), allowing to prepare at home for the examination and discharging of examinations, tasks, and tests during notes class were important for most children with MLD.

Do you experience difficulties with pitch skills? "In the past this was a problem, but we learned a trick to overcome these difficulties and know it goes fine." (Petra, 12 years)

"He has problems to remember. We have to repeat a lot. Enlarging paper and extra exercises also during the vacation period is needed." (Parents Dieter)

Finally during instruments class, a structured approach ( $n=1$ child, $n=9$ teachers), a good (nice) instrument, a nice textbook and nice music pieces, variation in the tasks and music scores, being in a group that fitted them in level and friendships, writing down the finger settings corresponding to the notes (possibly note names), allowing to play less or shorter pieces, simplifying the musical scores, adjusting the repertoire to the level and motivation of the pupil (possibility to play together), playing the music that is to be played to the pupil beforehand play it once, allowing to exercise with a metronome, allowing pupil to follow/tap the rhythm with his/her foot or have the teacher tap the rhythm for the pupil, adding text to the notes so that it becomes a song, and teaching longer or spreading it over a longer time (i.e., twice a week) were suggestions that helped children with MLD to learn and enjoy music.
"I have a metronome at home. That helps. Or I use my foot to time better." (Lore, 12 years)
"When I was younger the teacher wrote down the finger settings or the note names. But now I just have to work harder en study longer to get the rhythm and look what it gives." (Babet, 16 years)

All teachers and parents of subjects with MLD talked about the contact between them. Two teachers told that this was not easy. Four teachers described how they had 
regularly contact with the parents of the children. Also talking with other teachers on how to improve the music skills of children with MLD seemed important for teachers dealing with this population. This was never mentioned in the children without MLD.

3.6. Interview Results on Good Support during Notes Class and Instrument Class for Children Without MLD. Half of the control children told that they needed no additional help or explanations. None of them had extra lessons. Two children told that sometimes the teacher gave additional help for some aspects. Five children told that they had their own trick to determine the key of a piece. Also to keep the rhythm of a song, they found their own ways.

\section{Conclusion}

Music making is an activity requiring accurate timing skills. Children with MLD often have difficulties in perceiving rhythmic patterns in music. They report difficulties with pitch discrimination, note number detection and discrimination, not order detection, rhythm discrimination, rhythm coping, and pitch matching. However, some of them child are quite successful in playing an instrument. They also enjoy making music.

Teachers and parents mentioned intrinsic motivation, extrinsic motivation and self-efficacy as important protective factors to keep on studying an instrument. Some children with MLD were found to have a real musical talent and a very good musical ear and memory for sounds. However, all children with MLD seemed more dependent on the aid of parents, sibling, peers, and teachers. They needed more time to study, more practice, and a more structured approach. Control children without learning disabilities were often good in the reading of music notes and in the theoretical aspects of Music. They made their homework independently. Children with MLD never reported those things (see Figure 1).

STICORDI is an acronym referring to STI(mulation), $\mathrm{CO}$ (mpensation), R(emediation), and DI(spensation) (see [25]). With STICORDI devices "reasonable" adjustments are provided to ensure that students with DC are not placed at a substantial disadvantage compared to nondisabled peers. STICORDI devices for music teachers are summarized in Table 1.

In consideration of the findings of the present study, it is also important to note its limitations. First, it is not inconceivable that the children with MLD in the current study are not representative for all children with MLD. A lot of those children will not choose to play instrument. A second limitation of the study is that all the parents belonged to middle or high socioeconomic families. We are aware of the influence of this fact on the results of our study. Finally, one has to consider that this study was carried out in Flanders (Dutch-speaking Belgium). We are aware of the potential differences in musical education in other cultures, where other policies prevail and different services are available for families with a child with a disability.

From this study, we hope to give some suggestions to music teachers dealing with children with MLD during notes and instrument class. In addition, we aim to enhance the understanding for children with MLD trying to play an instrument.

Our data showed that children with MLD often experience more difficulties with musical skills. However, they seem to be able to play music if they work harder and get help from teachers and parents.

\section{References}

[1] A. D. Dowker, Individual Differences in Arithmetic. Implications for Psychology, Neuroscience and Education, Psychology Press, New York, NY, USA, 2005.

[2] J. Grégoire and A. Desoete, "Mathematical disabilities-an underestimated topic?" Journal of Psychoeducational Assessment, vol. 27, no. 3, pp. 171-174, 2009.

[3] W. J. Barbaresi, S. K. Katusic, R. C. Colligan, A. L. Weaver, and S. J. Jacobsen, "Math learning disorder: incidence in a population- based birth cohort 1976-82, Rochester, Minn," Ambulatory Pediatrics, vol. 5, no. 5, pp. 281-289, 2005.

[4] D. C. Geary, M. K. Hoard, L. Nugent, and D. H. Bailey, "Mathematical cognition deficits in children with learning disabilities and persistent low achievement: a five-year prospective study," Journal of Edcuationalal Psychology, vol. 104, pp. 206-223, 2011.

[5] R. S. Shalev, O. Manor, and V. Gross-Tsur, "Developmental dyscalculia: a prospective six-year follow-up," Developmental Medicine and Child Neurology, vol. 47, no. 2, pp. 121-125, 2005.

[6] D. C. Geary, M. K. Hoard, J. Byrd-Craven, L. Nugent, and C. Numtee, "Cognitive mechanisms underlying achievement deficits in children with mathematical learning disability," Child Development, vol. 78, no. 4, pp. 1343-1359, 2007.

[7] M. Forgeard, G. Schlaug, A. Norton, C. Rosam, and U. Iyengar, "The ralation between music and phonological processing in normal-reading and children with dyslexia," Music Perception, vol. 25, no. 4, pp. 383-390, 2008.

[8] L. Ganschow, J. Lloyd-Jones, and T. R. Miles, "Dyslexia and musical notation," Annals of Dyslexia, vol. 44, no. 1, pp. 185202, 1994.

[9] M. Habib and M. Besson, "What do music training and musical experience teach us about brain plasticity?" Music Perception, vol. 26, no. 3, pp. 279-285, 2009.

[10] S. Hébert, R. Béland, E. Beckett, L. L. Cuddy, I. Peretz, and J. Wolforth, "A case study of music and text dyslexia," Music Perception, vol. 25, no. 4, pp. 369-381, 2008.

[11] K. Overy, "Dyslexia and music: from timing deficits to musical intervention," Annals of the New York Academy of Sciences, vol. 999, pp. 497-505, 2003.

[12] K. Overy, R. I. Nicolson, A. J. Fawcett, and E. F. Clarke, "Dyslexia and music: measuring musical timing skills," Dyslexia, vol. 9, no. 1, pp. 18-36, 2003.

[13] B. S. Jaarsma and A. J. J. M. Ruijssenaars, "Kinderen met rekenproblemen en het leren van het muzikale notensysteem. Een exploratief onderzoek [Children with mathematical problems and the learning of the musical system]," Tijdschrift voor Orthopedagogiek, vol. 39, pp. 484-494, 2000.

[14] K. McCord and M. Fitzgerald, "Children with disabilities playing musical instruments. The entity from which ERIC acquires the content, including journal, organization, and conference names, or by means of online submission from the author," Music Educators Journal, vol. 92, no. 4, pp. 46-52, 2006. 
[15] I. Seidman, Interviewing as Qualitative Research, a Guide for Researchers in Education and the Social Sciences, Teachers College Press, 2006.

[16] M. Baudonck, A. Debusschere, B. Dewulf, F. Samyn, V. Vercaemst, and A. Desoete, Kortrijkse Rekentest-Revisie [Revised Kortrijk Arithmetic Test], Revalidatiecentrum Overleie, Kortrijk, Belgium, 2006.

[17] T. De Vos, TTR. Tempotest Rekenen [Arithmetic Number Fact Test], Swets \& Zeitlinger, Lisse, The Netherlands, 1992.

[18] P. Stock, A. Desoete, and H. Roeyers, "Detecting children with arithmetic disabilities from kindergarten: evidence from a 3year longitudinal study on the role of preparatory arithmetic abilities," Journal of Learning Disabilities, vol. 43, no. 3, pp. 250-268, 2010.

[19] A. Desoete, A. Ceulemans, F. De Weerdt, and S. Pieters, "Can we predict mathematical learning disabilities from symbolic and non-symbolic comparison tasks in kindergarten?" British Journal of Educational Psychology, vol. 82, pp. 64-81, 2012.

[20] B. T. Brus and M. J. M. Voeten, Eén-Minuut-Test: Vorm A en B [One Minute Reading Test], Berkhout., Nijmegen, The Netherlands, 1999.

[21] K. P. Van den Bos, L. H. C. Spelberg, A. J. M. Scheepstra, and J. R. de Vries, De Klepel: Vorm A en B, Berkhout, Nijmegen, The Netherlands, 1994.

[22] J. Geelhoed and P. Reitsma, PI-Dictee [PI-Dictation], Harcourt Test Publishers, Lisse, The Netherlands, 2000.

[23] M. B. Miles and A. M. Huberman, Qualitative Data Analysis, an Expanded Sourcebook, Sage, London, UK, 2nd edition, 1994.

[24] D. Mortelmans, Handboek Kwalitatieve Onderzoeksmethoden [Handbook Qualitative Resarch Methods], Acco, Leuven, Belgium, 2007.

[25] A. Desoete, "Students with mathematical disabilities in Belgium: from definition, classification and assessment to STICORDI devices," in Advances in Learning and Behavioral Disabilities, T. E. Scruggs and M. A. Mastropieri, Eds., vol. 20, pp. 181-222, International Perspectives Amsterdam \& Elsevier Press, Oxford, UK, 2007. 


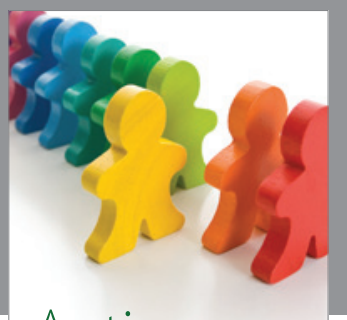

Autism

Research and Treatment
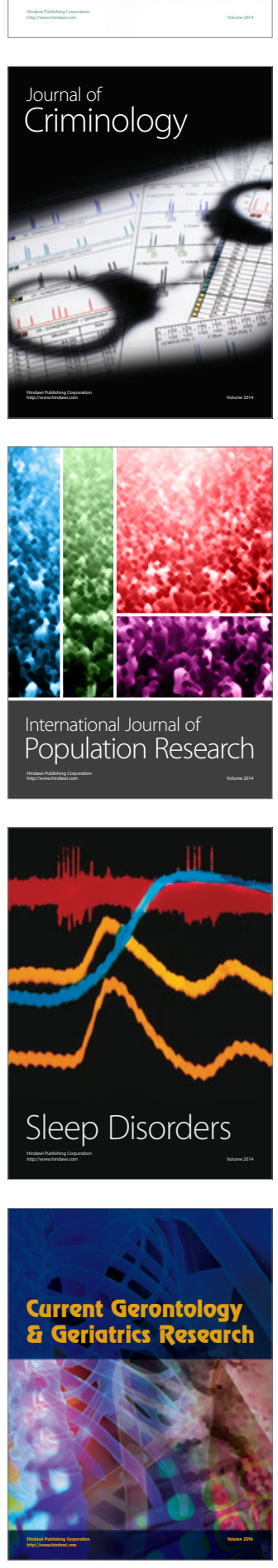
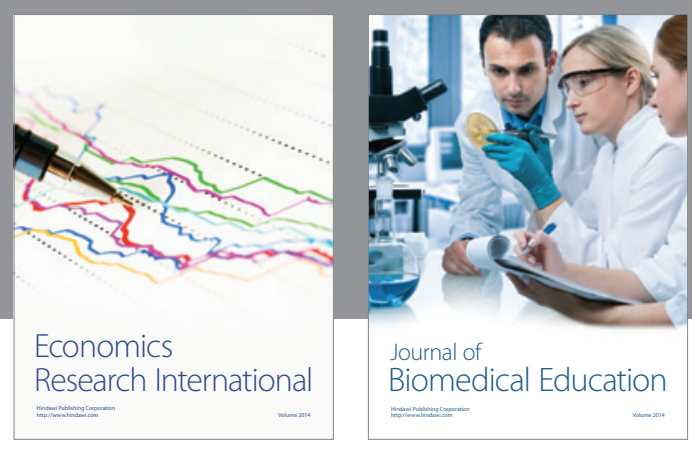

Journal of

Biomedical Education

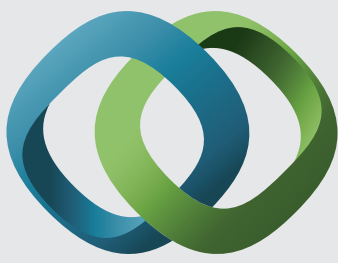

\section{Hindawi}

Submit your manuscripts at

http://www.hindawi.com
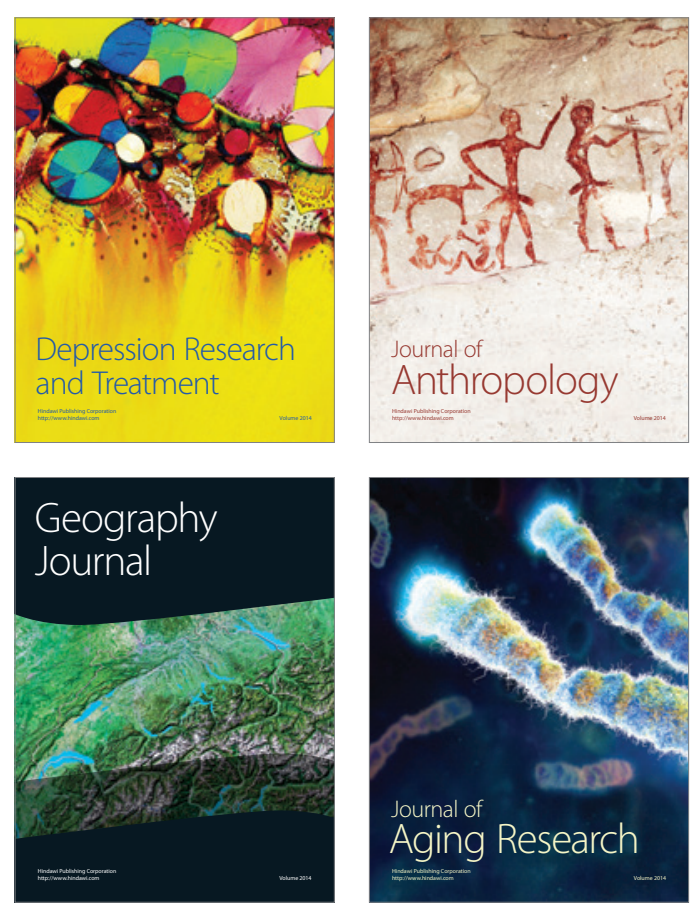

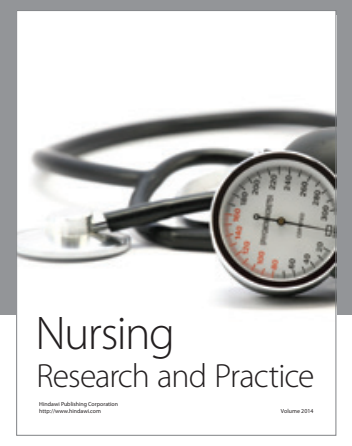

Nursing

Research and Practice

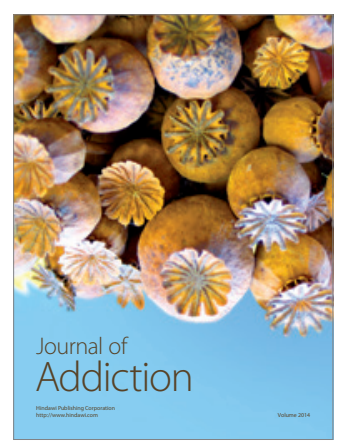

Child Development

Research

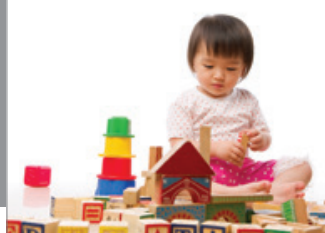

迥
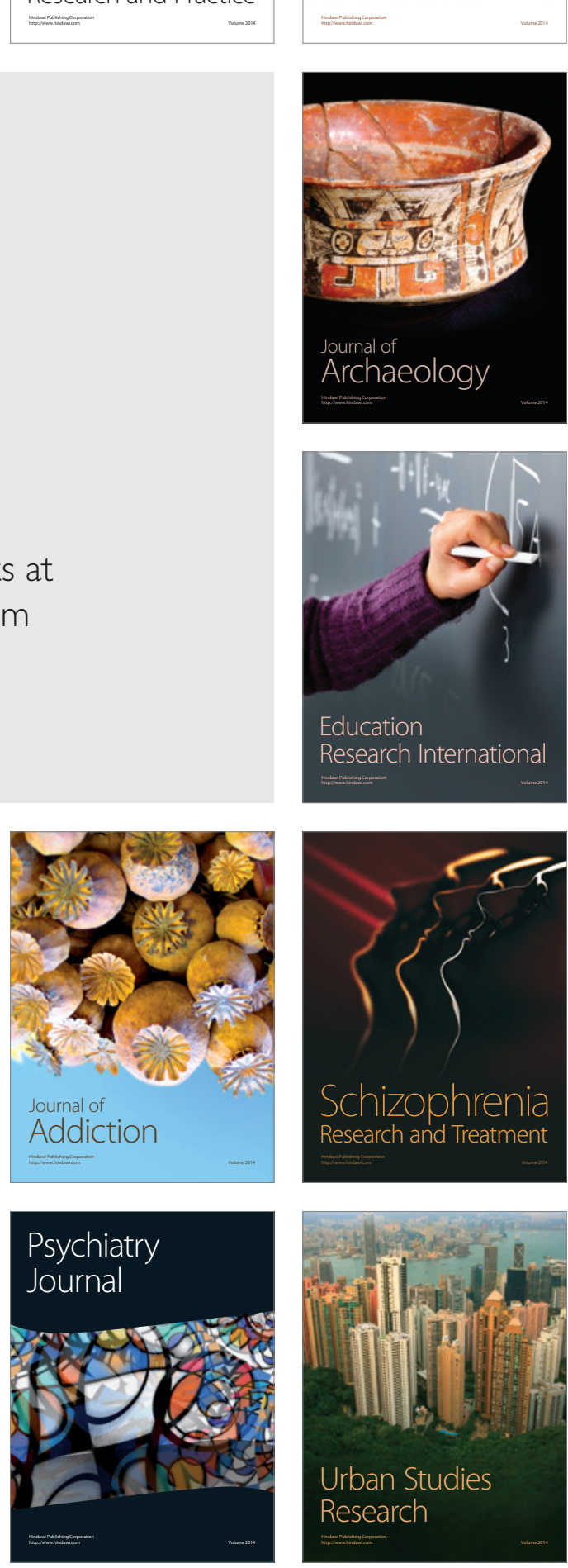